\title{
A comparison of optical and coherent HF radar backscatter observations of a post-midnight aurora
}

\author{
S. E. Milan ${ }^{1}$, M. Lester ${ }^{1}$, J. Moen ${ }^{2}$ \\ 1 Department of Physics and Astronomy, University of Leicester, Leicester, LE1 7RH, UK \\ 2 UNIS, PO Box 156, N-9170 Longyearbyen, Norway
}

Received: 17 January 1997 / Revised: 30 April 1997 / Accepted 12 May 1997

\begin{abstract}
A poleward-progressing $630 \mathrm{~nm}$ optical feature is observed between approximately 0100 UT and 0230 UT (0400 MLT to 0530 MLT) by a meridianscanning photometer (MSP) located at Ny Ålesund, Svalbard. Simultaneous coherent HF radar measurements indicate a region of poleward-expanding backscatter with rapid sunward plasma flow velocity along the MSP meridian. Spatial maps of the backscatter indicate a stationary backscatter feature aligned obliquely with respect to the MSP meridian, which produces an impression of poleward-expansion as the MSP progresses to later MLT. Two interpretations of the observations are possible, depending on whether the arc system is considered to move (time-dependent) or to be stationary in time and apparent motion is produced as the MSP meridian rotates underneath it (timeindependent). The first interpretation is as a poleward motion of an east-west aligned auroral arc. In this case the appearance of the region of backscatter is not associated with the optical feature, though the velocities within it are enhanced when the two are co-located. The second interpretation is as a polar arc or theta aurora, common features of the polar cap under the prevailing IMF northwards conditions. In this case the backscatter appears as an approximately $150 \mathrm{~km}$ wide region adjacent to the optical arc. In both interpretations the luminosity of the optical feature appears related to the magnitude of the plasma flow velocity. The optical features presented here do not generate appreciable HF coherent backscatter, and are only identifiable in the backscatter data as a modification of the flow by the arc electrodynamics.
\end{abstract}

\section{Introduction}

The SuperDARN coherent HF radars (Greenwald et al., 1995) are designed to employ backscatter from highlatitude field-aligned ionospheric plasma density irregularities (radar aurora) as tracers of the bulk plasma motion under the influence of the convection electric field, and hence as a diagnostic tool for the investigation of large-scale magnetospheric-ionospheric coupling. The Co-operative UK Twin Located Auroral Sounding System (CUTLASS) forms the eastern-most pair of radars (named Finland and Iceland East) of SuperDARN, and is the focus of the present study. The ionospheric irregularities are formed by plasma instabilities, the generating mechanism being dependent on altitude. At $E$ region altitudes the ion-neutral collision frequency is sufficiently high to constrain the ion population to the neutral flow speed, whereas the electrons move under the influence of the convection electric field with an $\mathbf{E} \times \mathbf{B}$ drift. This differential flow between ions and electrons gives rise to the two-stream (or Farley-Buneman) instability (Farley, 1963; Buneman, 1963). At $F$ region altitudes the ion-neutral collision frequency is low, so both ions and electrons move with the $\mathbf{E} \times \mathbf{B}$ drift and the two-stream instability is not generated. At these altitudes the gradient-drift instability (Ossakow and Chaturvedi, 1979) is the predominant small-scale irregularity generating mechanism. Such irregularities are produced in the electron density gradients at the edges of large $(\sim 10-100 \mathrm{~km})$ scale $\mathrm{F}$ region irregularities, which may be produced by structured soft particle precipitation (Tsunoda, 1988).

Auroral arcs are the optical manifestation of particle precipitation and hence a comparison of optical observations and $\mathrm{HF}$ radar backscatter observations is of interest, not only as a multi-instrument investigation of large-scale geophysical processes, but also as a study of possible irregularity generating mechanisms. Optical arcs within the auroral zone are, in general, aligned 
along the plasma flow direction at auroral latitudes, i.e. east-west or L-shell aligned. Two types of arc have been proposed (Marklund, 1984). In both, the luminous feature of an arc is the optical manifestation of an upward field-aligned current (FAC) sheet carried by precipitating electrons, enhancing the ionospheric conductivity along its length. In the first arc type, the polarisation or anti-correlation (so named due to the anti-correlation between electron precipitation and electric field, De la Beaujardiere et al., 1977) type arc, the FAC is small as a polarisation electric field is created across the high conductivity region, suppressing the convection electric field. In this case, current flow in the ionosphere is along the arc. In the second arc type, Pedersen currents provide current closure between the upward FAC and an adjacent downward FAC sheet, carried by up-going cold ionospheric electrons (Opgenoorth et al., 1990). In the post-midnight sector, a region of southward convection electric field at auroral latitudes, the downward FAC sheet forms poleward of the upward FAC, and leads to a narrow $(10-100 \mathrm{~km})$ region of enhanced southward electric field and hence eastward plasma flow.

Within the polar cap, sun-aligned optical arcs are observed, generally during periods when IMF $B_{z}>0 \mathrm{nT}$ (Ismail et al., 1977; Gussenhoven, 1982; Valladares and Carlson, 1991; Carlson, 1994). Such arcs are sometimes termed theta aurora due to their distinctive shape (Frank et al., 1986). The upward FAC sheets of polar, or high latitude, arcs are associated with non-zero divergence in the convection electric field, and hence flow-shears in the convection pattern (Burch et al., 1979; Burke et al., 1982; Carlson et al., 1988; Hones et al., 1989). As such, polar arcs often represent the boundaries between different magnetospheric regions and hence facilitate the investigation of the as-yet poorly understood magnetospheric processes obtaining during IMF northward conditions.

The present study examines the observations of ionospheric convection flow measured by the CUTLASS Finland HF radar in the vicinity of a polewardprogressing optical luminosity feature observed by a meridian-scanning photometer located at Ny Ålesund, Svalbard. The comparison of both observational techniques allows possible interpretations of the observations that would not have been possible with either data set independently.

\section{The CUTLASS radars and the Svalbard meridian-scanning photometer}

The two CUTLASS radars, located at Hankasalmi $\left(62.3^{\circ} \mathrm{N}, 26.6^{\circ} \mathrm{E}\right)$ in Finland and Pykkvibær $\left(63.8^{\circ} \mathrm{N}\right.$, $\left.20.5^{\circ} \mathrm{W}\right)$ in Iceland, each comprise two arrays of logperiodic antennas, a main array of 16 antennas, with both transmit and receive capability, and an interferometer array of four antennas with receive capability only. The radars can operate in the HF band between $8 \mathrm{MHz}$ and $20 \mathrm{MHz}$, though during the present study they were operating near $10 \mathrm{MHz}$. The antennas in each array are phased in relation to one another to form an antenna pattern in which the maximum gain (beam position) has one of 16 azimuthal pointing directions separated by approximately $3.2^{\circ}$, distributed symmetrically about the radar boresites of $-12^{\circ}$ (i.e. west of north) and $30^{\circ}$ (east of north) for the Finland and Iceland radars respectively. In the normal scan mode of the radars, the 16 beams are sounded with a dwell time of $7 \mathrm{~s}$, producing field-of-view maps of backscatter, with an azimuthal coverage of over $50^{\circ}$, every $2 \mathrm{~min}$. Typically, 75 range gates are sampled for each beam, with a pulse length of $300 \mu \mathrm{s}$, corresponding to a gate length of $45 \mathrm{~km}$, and a lag to the first gate of $1200 \mu \mathrm{s}$ $(180 \mathrm{~km})$. In this configuration the maximum range of the radars is approximately $3555 \mathrm{~km}$, with each field-ofview containing 1200 cells. Figure 1 illustrates the locations of the fields-of-view of the two radars. The statistical location of the auroral oval (Feldstein and Starkov, 1967; Holzworth and Meng, 1975) at 01 UT is also shown in Fig. 1 for quiet geomagnetic conditions $\left(K_{\mathrm{p}}=1\right)$. A 7 pulse scheme is transmitted and analysis of the auto-correlation function (ACF) of the returned signals yields backscatter Doppler spectra, from which can be derived the spectral characteristics of power, lineof-sight Doppler velocity, $v_{l o s}$, and spectral width, $\Delta v$ (Hanuise et al., 1993). The Doppler velocity gives an estimate of the radar line-of-sight component of the

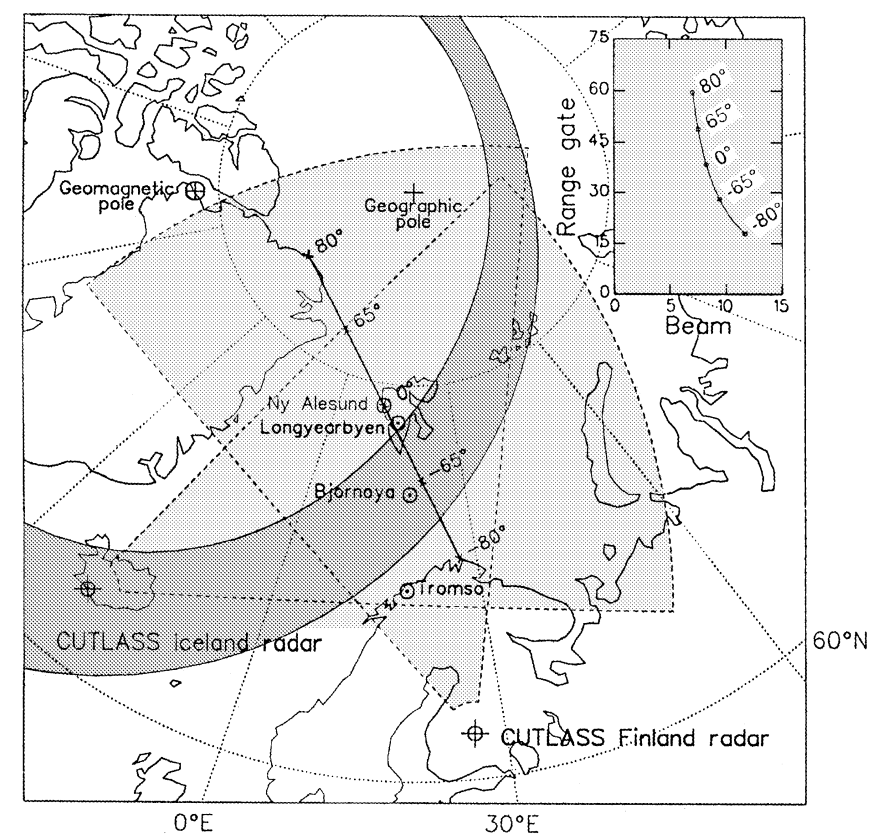

Fig. 1. The locations of the fields-of-view of the CUTLASS radars and the meridian of the Ny Alesund MSP, projected to $250 \mathrm{~km}$ altitude. Numbers to the right of MSP meridian indicate the location of the projection of zenith angles $0^{\circ}, 65^{\circ}$ and $80^{\circ}$. Also illustrated is the statistical location of the quiet $\left(K_{\mathrm{p}}=1\right)$ auroral oval at $01 \mathrm{UT}$. The IMAGE magnetometer site at Bjørnøya is indicated as well as the EISCAT sites Tromsø and Longyearbyen for reference. The inset panel indicates the mapping of the MSP meridian into the beam/gate coordinates of the Finland radar field-of-view; this information is employed for the mapping of radar backscatter onto the MSP meridian in Fig. 3 
plasma convection velocity (Villain et al., 1985; Ruohoniemi et al., 1987).

The meridian-scanning photometer (MSP) located at Ny Ålesund $\left(78.9^{\circ} \mathrm{N}, 11.9^{\circ} \mathrm{E}\right)$, Svalbard, scans roughly along the magnetic meridian, $35^{\circ}$ west of geographic north, to $10^{\circ}$ above the northern and southern horizons, with a scan period of $18 \mathrm{~s}$. In the following text, the convention that positive (negative) zenith angles refer to north (south) of the MSP is followed. The line-of-sight intensities of $630.0 \mathrm{~nm}$ (red) and $557.7 \mathrm{~nm}$ (green) auroral emissions are measured, corresponding to transitions from the ID and IS metastable states of atomic oxygen (OI). The present study concentrates on the red line observations, associated with $\mathrm{F}$ region emissions, often assumed to originate from an altitude of $250 \mathrm{~km}$. The meridian of the MSP, projected to $250 \mathrm{~km}$ altitude is included in Fig. 1. An inaccuracy in the assumed emission altitude produces errors in the latitude mapping of the MSP observations at the extremes of the meridian; at $0^{\circ}$ zenith angle the mapping is independent of emission altitude. Varying the emission altitude by $\pm 50 \mathrm{~km}$ (i.e. to $200 \mathrm{~km}$ or $300 \mathrm{~km}$ ) changes the mapping of the $\pm 65^{\circ}$ and $\pm 80^{\circ}$ zenith angle points by $\pm 0.5^{\circ}$ and $\pm 1^{\circ}$ of latitude respectively. Such variations are not significant for the interpretation of data presented in this study. The green line observations are consistent with the red line observations when a projection altitude of approximately $110 \mathrm{~km}$ is assumed.

\section{Observations}

The interval considered in the present study is 00 UT to 03 UT on 25 November 1995. This interval was geomagnetically quiet, with $K_{\mathrm{p}}=1$ and $\sum K_{\mathrm{p}}$ for the previous $24 \mathrm{~h}$ of $2+$, and with a weakly northward IMF $\left(B_{\mathrm{x}} \approx 3\right.$ $\mathrm{nT}$ to $4 \mathrm{nT}, B_{\mathrm{y}} \approx-1 \mathrm{nT}, B_{\mathrm{z}} \approx 1 \mathrm{nT}$ to $2 \mathrm{nT}$ ) as measured by the WIND spacecraft. Data from the IMAGE magnetometer chain were examined for evidence of substorm activity. A $100 \mathrm{nT} \mathrm{X}$-component negative bay was observed at Bjørnøya (the location of which is indicated in Fig. 1) between 0000 UT and 0045 UT, indicating a weak and localised westward electrojet, with lower latitude stations suggesting a weaker eastward electrojet. No Pi2 activity was detected and no substorm signatures were observed in geosynchronous satellite data. If weak substorm activity did occur at $\sim 00 \mathrm{UT}$ then the interval of most interest in this study, 0045 UT to $0130 \mathrm{UT}$, occurred during the substorm recovery phase.

\subsection{Comparison of observations along the MSP meridian}

The observations of the Ny Allesund meridian scanning photometer from the interval of study are illustrated in Fig. 2. Between 00 UT and 03 UT the MSP progressed from 03 MLT to 06 MLT. Between 0000 UT and 0050 UT the MSP observed a series of auroral arcs towards the south with peak intensity at a zenith angle equatorward of $-50^{\circ}$ and the poleward border near a zenith

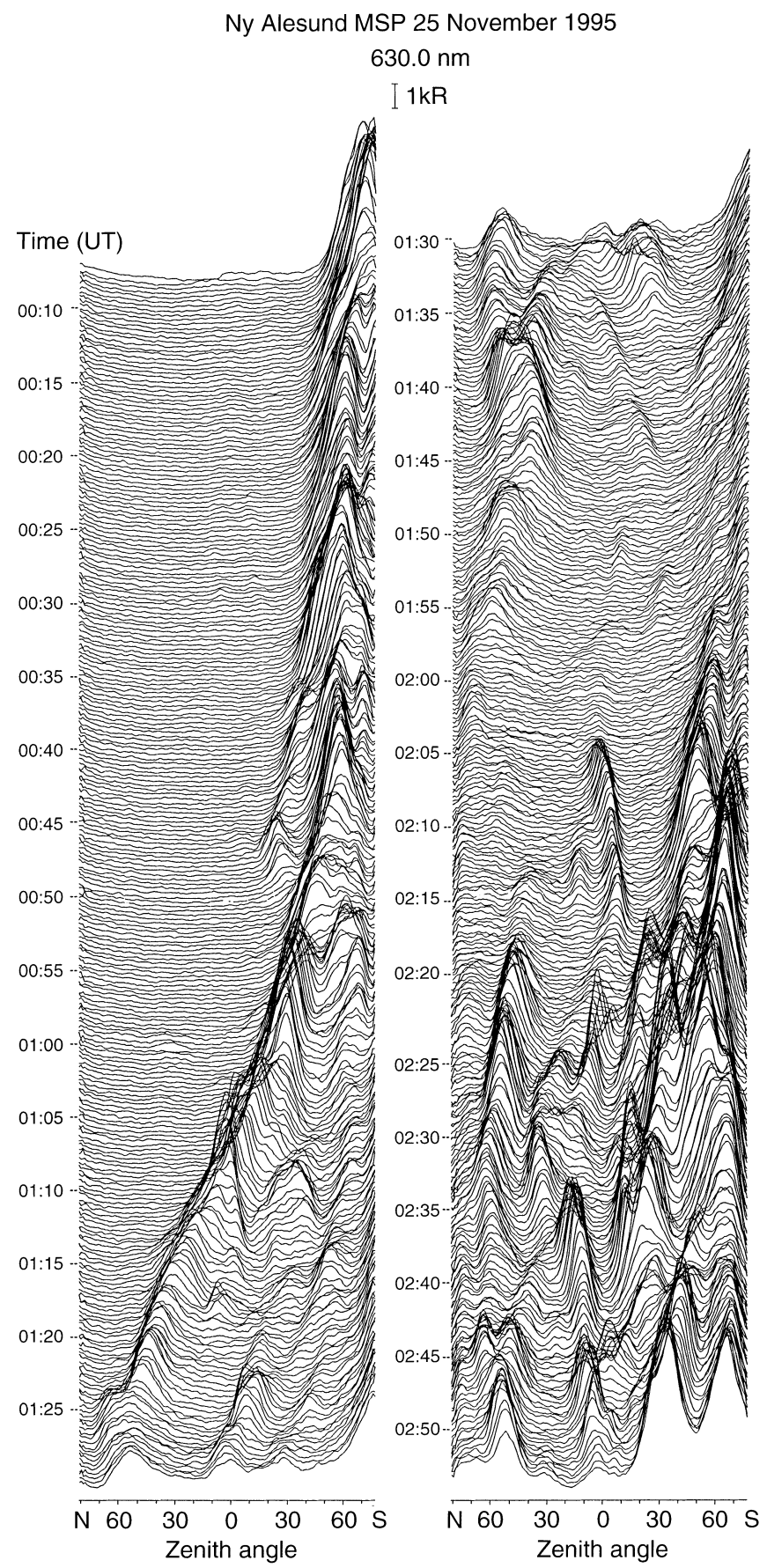

Fig. 2. The Ny Ålesund MSP red line $(630 \mathrm{~nm})$ emission observations for the period 00 UT to 03 UT on 25 November 1995

angle of $-30^{\circ}$. The most poleward feature decreased in intensity such that at 0050 UT the poleward border was associated with the most intense feature at approximately $-50^{\circ}$. Thereafter this feature moved poleward in a fairly steady manner, reaching a zenith angle of $50^{\circ}$ to the north by 0125 UT. During this poleward progression the observed intensity of the red emissions fell from approximately $6 \mathrm{kR}$ to $1 \mathrm{kR}$. After $0135 \mathrm{UT}$ the arc stepped equatorward briefly, to $40^{\circ} \mathrm{N}$ zenith angle, brightening to approximately $2 \mathrm{kR}$, before continuing its poleward motion to $70^{\circ} \mathrm{N}$ zenith angle and dimming 
to $1 \mathrm{kR}$ by $0200 \mathrm{UT}$. The arc remained at the northernmost extreme of the meridian until 0230 UT after which it disappeared. From approximately 01 UT onwards, a second arc was observed at the southern-most extreme of the meridian, which varied in brightness from $3 \mathrm{kR}$ at $0100 \mathrm{UT}$ to $8 \mathrm{kR}$ at $0210 \mathrm{UT}$. Between the polewardprogressing and southern-most arcs faint luminosities $(\sim 1 \mathrm{kR})$ were observed between $0110 \mathrm{UT}$ and $0140 \mathrm{UT}$ and brighter features ( $3 \mathrm{kR}$ to $8 \mathrm{kR})$ after $0205 \mathrm{UT}$. The zenith angles of peaks in the luminosity observed on the MSP scan between 00 UT and 03 UT are illustrated in Fig. 3. The middle panel includes the poleward-progressing arc between $01 \mathrm{UT}$ and $02 \mathrm{UT}$.

The Finland radar line-of-sight velocity measurements for the same interval are also presented in Fig. 3, projected onto the meridian scanned by the MSP at an altitude of $250 \mathrm{~km}$. The mapping of the MSP meridian onto the cells of the Finland radar field-of-view is illustrated in the inset panel of Fig. 1; the zenith angle variation in the size of the Finland cells in Fig. 3 is a function of this mapping. Between 00 UT and 01 UT backscatter with near-zero velocity was observed at MSP zenith angles of $-50^{\circ}$ to $-80^{\circ}$. After 0104 UT this region of backscatter expanded polewards reaching an MSP zenith angle of $0^{\circ}$ by 0110 UT. Associated with this expanding region were negative (polewards) line-of-sight plasma drift velocities of $400 \mathrm{~m} \mathrm{~s}^{-1}$ to $1000 \mathrm{~m} \mathrm{~s}^{-1}$. These velocities persisted until 0115 UT after which they decreased to between $0 \mathrm{~m} \mathrm{~s}^{-1}$ and $400 \mathrm{~m} \mathrm{~s}^{-1}$. Backscatter continued to be observed between MSP zenith angles of $-10^{\circ}$ to $-70^{\circ}$ until $0156 \mathrm{UT}$, and a region of backscatter was observed between MSP zenith angles of $10^{\circ}$ to $50^{\circ}$ north of Svalbard between 0130 UT and 0145 UT associated with near-zero velocities. A narrow region of backscatter was observed at the MSP zenith angle of approximately $-70^{\circ}$ between 0150 UT and $0216 \mathrm{UT}$ and later, $0222 \mathrm{UT}$ to $0238 \mathrm{UT}$, predominantly between zenith angles $-50^{\circ}$ to $-60^{\circ}$, again with low velocities. The spectral widths measured by the radar tended to be low, less than $150 \mathrm{~m} \mathrm{~s}^{-1}$, though this increased to $250 \mathrm{~m} \mathrm{~s}^{-1}$ at the leading edge of the poleward-progressing region of backscatter. Limited
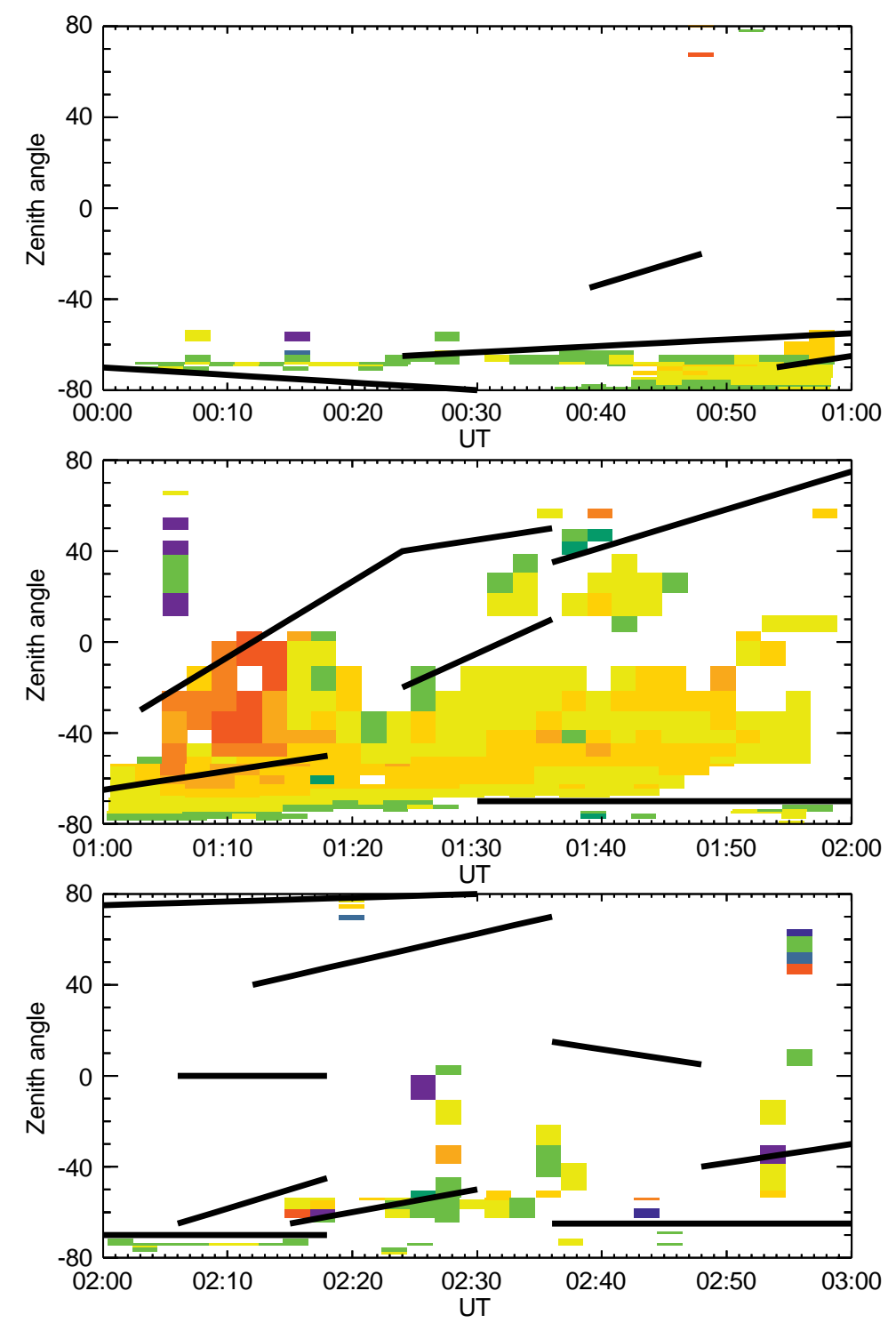

Fig. 3. The variation in zenith angle of optical features along the MSP meridian during the interval 00 UT and 03 UT (dark lines); the poleward progressing feature is predominantly seen between 0100 UT and 0230 UT. Also superimposed on these axes is the projection of line-of-sight backscatter velocities measured by the CUTLASS Finland radar along the MSP meridian for a projection altitude of $250 \mathrm{~km}$ 
and sporadic backscatter was observed along the MSP meridian in the Iceland radar field-of-view. This backscatter tended to be of near-zero velocity.

There is no clear one-to-one relationship between the optical and $\mathrm{HF}$ radar observations, though common features can be found in both data sets. Between 00 UT and 01 UT both backscatter and luminosity are observed at the southern-most extreme of the MSP meridian, followed between 0100 UT and 0120 UT by a poleward motion of the arc and a poleward expansion of the region of backscatter. The motion of the arc continues to zenith angles of $60^{\circ}$ and above, though the expansion of the region of backscatter extends only to overhead the MSP. The most equatorward optical arc, visible until $0220 \mathrm{UT}$, continues to produce radar backscatter until 0216 UT, and backscatter appears during the period 0215 UT to 0239 UT between MSP zenith angles of $-50^{\circ}$ and $-60^{\circ}$, possibly corresponding to a bright arc observed optically. Conversely, periods occur when the correlation between the optical and backscatter observations is poor. During the period 0120 UT to 0205 UT, between the poleward-moving and equatorward-most optical arcs is a region of low luminosity. This region, up to zenith angles of $-10^{\circ}$, is filled with radar backscatter. After 0200 UT very little radar backscatter is observed, despite the appearance of many bright arcs along the MSP meridian after 0205 UT.

\subsection{Spatial comparison of observations}

Maps of the HF backscatter within the whole field-ofview of the Finland radar, and not just along the MSP meridian, put the optical observations in a spatial context. Figure 4 illustrates the radar backscatter from six scans between 0046 UT and 0124 UT, projected on AACGM (based on Baker and Wing 1989) geomagnetic latitude (GMLAT) and magnetic local time (MLT) coordinates. Also indicated is the location of $\mathrm{Ny}$ Alesund MSP meridian, projected to $250 \mathrm{~km}$ altitude, and the statistical location of the auroral oval for $K_{\mathrm{p}}=1$. The same backscatter feature is present throughout most of the interval 0036 UT and 0124 UT, with no apparent variation in its location within the GMLAT/MLT frame. Between $67^{\circ}$ to $72^{\circ}$ GMLAT backscatter extends from 0230 MLT to 0400 MLT, whilst above $72^{\circ}$ GMLAT the backscatter extends to between $78^{\circ}$ and $80^{\circ}$ GMLAT and from 0400 MLT to 0500 MLT. The velocities of the backscatter are consistent with westward zonal flow between $72^{\circ}$ and $70^{\circ}$ GMLAT, eastward zonal flow below $70^{\circ}$ GMLAT, and rapid sunward flow (along the line-of-sight of the radar) poleward of this. The zonal flow region is consistent with the IMAGE magnetometer observations described above. Sporadic near-zero velocity backscatter observed by the Iceland radar, coincident with the

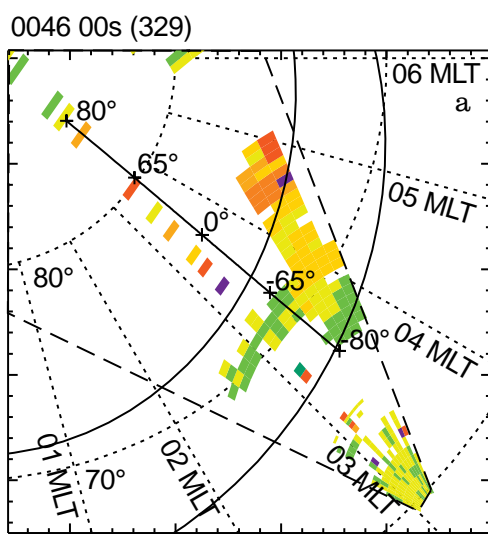

0116 00s (329)

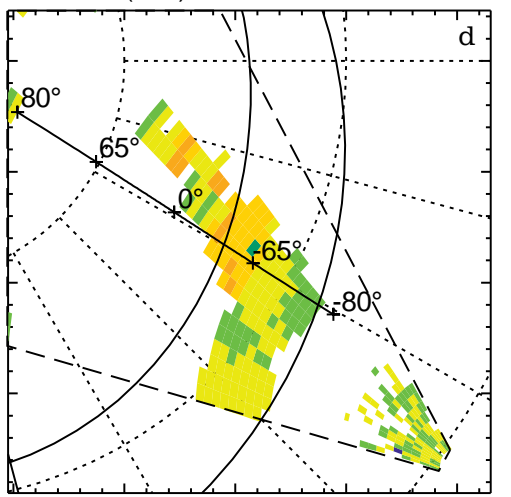

0102 00s (329)

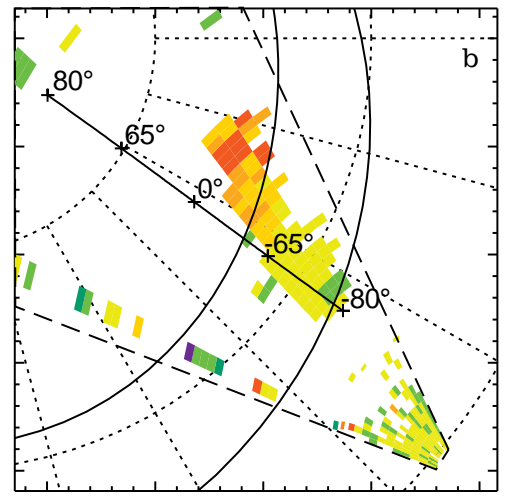

0119 59s (329)

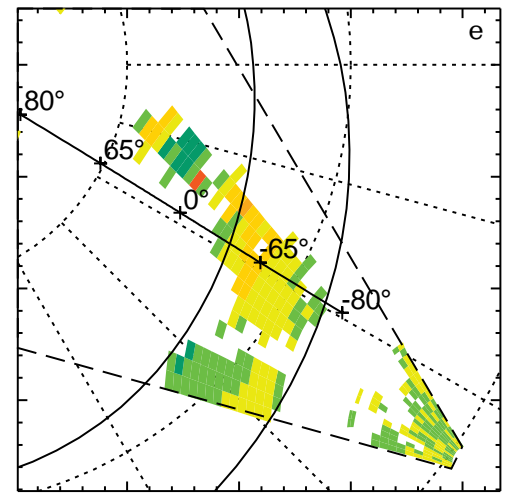

$011200 s(329)$

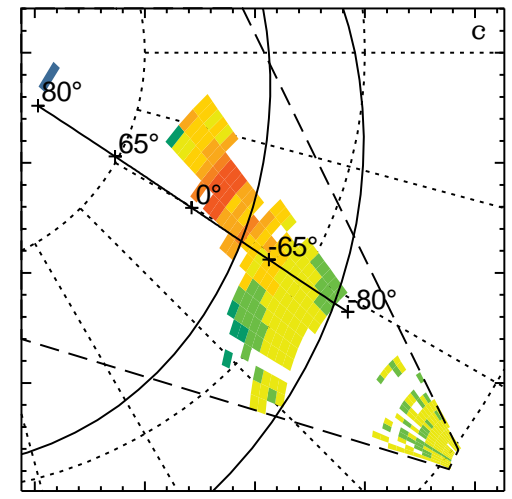

012359 s (329)

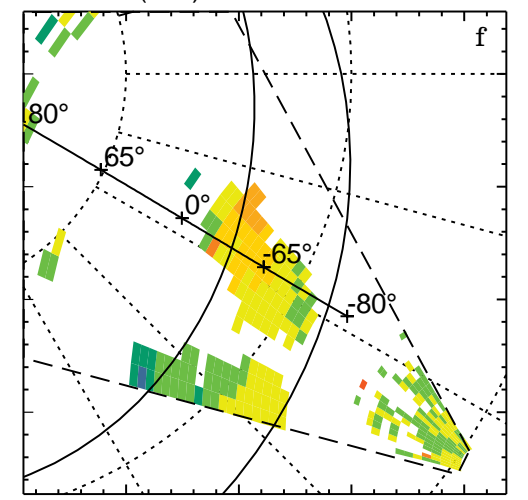

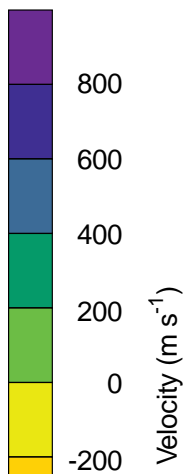

$-400$

$-600$

$-800$

Fig. 4. Spatial plots, in GMLAT/MLT coordinates, of the CUTLASS Finland backscatter at six times between 0046 UT and 0124 UT. The dashed lines represent the edges of the radar field-of-view. The locations of the MSP meridian and the auroral oval $\left(K_{\mathrm{p}}=1\right)$ are also indicated 
poleward sunward-flow region, suggests that flow is generally along the line-of-sight of the Finland radar. The spectral width (not shown) of the sunward-flow backscatter is high, $250 \mathrm{~m} \mathrm{~s}^{-1}$ to $500 \mathrm{~m} \mathrm{~s}^{-1}$, and of the zonal-flow region is low, less that $100 \mathrm{~m} \mathrm{~s}^{-1}$. At $0046 \mathrm{UT}$ the MSP meridian is located to the west of the sunwardflow backscatter, though cuts through the region of zonal flow. Later, as the MSP meridian moves to later magnetic local time, it becomes coincident with the sunward-flow region at approximately 0102 UT and cuts through several degrees of latitude of the sunward flow at 0112 UT. The orientation of this region of backscatter with respect to the MSP meridian causes an apparent rapid poleward motion of the backscatter along the meridian, as seen in Fig. 3 between 0104 UT and 0112 UT. Equatorward of the region of rapid flow observed along the MSP meridian is slower flow, below $-60^{\circ}$ zenith angle, corresponding to the region of zonal flow.

At 0112 UT the region of sunward flow extends to $78^{\circ}$ GMLAT, though is only coincident with the MSP meridian as far poleward as $75^{\circ}$ GMLAT (approximately MSP zenith angle $0^{\circ}$, the maximum poleward extent of this backscatter in Fig. 3). If this situation remained static then, as the MSP meridian moved to later local times, the backscatter feature would extend along the MSP meridian up to zenith angles of approximately $60^{\circ}$. However, after 0112 UT the velocities observed in the sunward-flow region decrease (see 0116 UT and 0120 UT in Fig. 4) before the backscatter fades away (0124 UT). This slowing of the flow and disappearance of the backscatter is observed along the MSP meridian between 0115 UT and 0120 UT in Fig. 3. This region of zonal flow equatorwards of the sunward-flow region continues to be observed by the radar until 0344 UT, and it is this backscatter that is observed along the MSP meridian between 0120 UT and 0157 UT (Fig. 3).

The line-of-sight flow velocity within the sunwardflow region is not constant with latitude, but has velocity enhancements which move with time (see Fig. 4). A stack-plot of velocity as a function of range gate along beams 10 and 11 for times between 0104 UT and 0122 UT (Fig. 5) indicates a poleward progression of one such flow enhancement, the thick dashed line representing a fit-by-eye to this motion. In this diagram range gates 25 and 50 map to geomagnetic latitudes of approximately $68^{\circ} \mathrm{N}$ and $79^{\circ} \mathrm{N}$ respectively, the vertical dashed line at range gate 30 demarcating the zonal and meridional flow regimes at $72^{\circ} \mathrm{N}$. Before 0114 UT this flow enhancement has velocities of up to $1 \mathrm{~km} \mathrm{~s}^{-1}$, though later these velocities decrease in line with the overall decrease in flow velocity mentioned above.

\section{Two opposing interpretations of the data}

Depending on whether the motions of optical features along the MSP meridian are considered to be due to temporal or spatial variations, essentially whether the arc system is time-dependent or time-independent, leads to two possible interpretations of the observations. Each interpretation will be presented in turn and the geo-

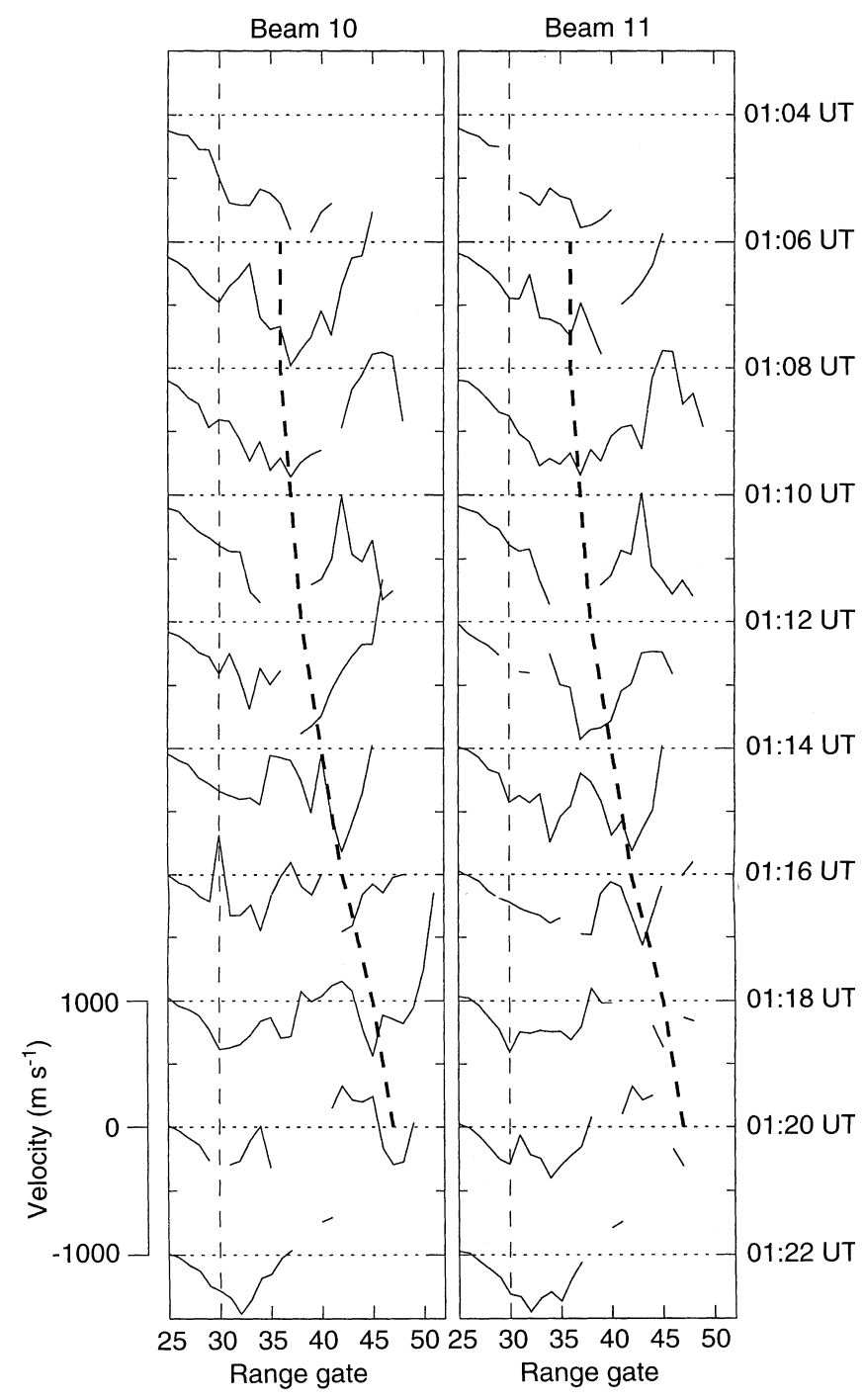

Fig. 5. Stack plots of line-of-sight backscatter velocity as a function of range gate of beams 10 and 11 between 0104 UT and 0122 UT. Range gates 25 and 50 correspond to approximately $68^{\circ} \mathrm{N}$ GMLAT and $79^{\circ} \mathrm{N}$ GMLAT. The vertical dashed line indicates the demarcation of zonal and meridional flow at $72^{\circ} \mathrm{N}$. A poleward-progressing velocity enhancement is observed, the thick dashed line being a fit-byeye to this poleward motion

physical conditions under which either interpretation would be expected is discussed.

\subsection{Temporal variations: poleward expansion in response to substorm}

The leading edge of the poleward expanding region of backscatter between 0104 UT and 0114 UT has associated with it line-of-sight plasma drift velocities of the order of $400 \mathrm{~m} \mathrm{~s}^{-1}$ to $1000 \mathrm{~m} \mathrm{~s}^{-1}$. The rate of motion of this leading edge, and of the optical polewardprogressing arc when projected to $250 \mathrm{~km}$ altitude, however, have a velocity of the order $200 \mathrm{~m} \mathrm{~s}^{-1}$ to $250 \mathrm{~m} \mathrm{~s}^{-1}$. If the arc is L-shell aligned then there must be a considerable zonal component of the plasma flow 
associated with the arc, the line-of-sight velocities observed by the radar being the meridional component of this flow, accounting for the discrepancy between plasma flow and arc velocity (see Sect. 1). Exact estimates of the zonal component of the flow are difficult to make, however, as arcs have been observed for which a significant plasma flow tangential to the arc is present (Gazey et al., 1995; Frey et al., 1996). A schematic of this situation is presented in Fig. 6. As the MSP meridian is to the west of the region of backscatter, it must be assumed that the arc has constant geomagnetic latitude along its length to allow the location of the optical feature to be compared with the observed flows. If such a projection is made, the poleward progressing optical feature moves poleward at a rate similar to the poleward motion of the flow enhancement observed in the radar backscatter (see Fig. 5), though an optical emission altitude of $350 \mathrm{~km}$ has to be assumed for the best correspondence. The arc observed between 0040 UT and $0050 \mathrm{UT}$ at approximately $-30^{\circ}$ zenith angle is also possibly associated with a flow enhancement. If the equatorward edge of the velocity enhancement was colocated with the optical feature, these observations would be consistent with an enhanced-E arc as described in Sect. 1. However, the mapping is not considered sufficiently accurate to verify this possibility.

The decrease in the background flow velocity and the flow enhancement, and the subsequent disappearance of the backscatter after 0112 UT are possibly linked to the decrease in optical luminosity observed during the poleward motion of the poleward-most arc, specifically between 0103 UT and 0125 UT (sec Sect. 3.1). In the context of a simple Ohms law relationship, the lumi-

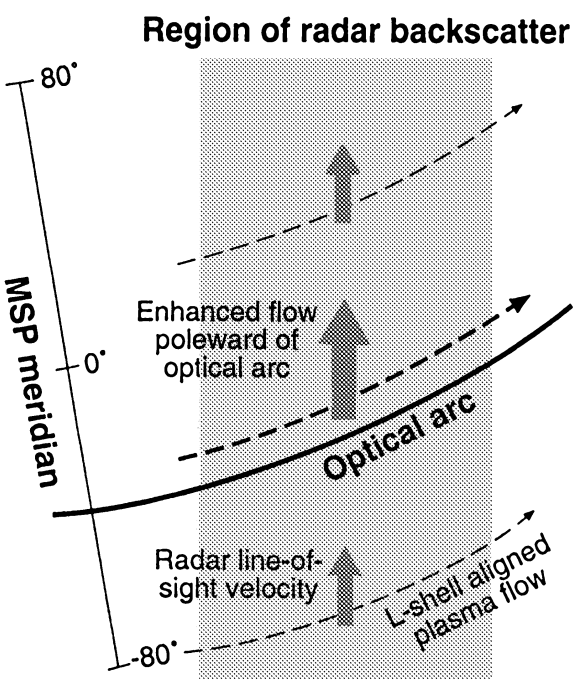

Fig. 6. A schematic representation of the relative locations of the MSP meridian and the Sunward-flow region of backscatter under the time dependent interpretation of the observations. To compare backscatter velocities with the location of the optical features observed along the MSP meridian, the arc and plasma flow must both be assumed to be L-shell aligned. In this interpretation, a velocity enhancement might be observed adjacent to and poleward of the optical arc. nosity of the arc should be related to the magnitude of the upward FAC, a decrease in luminosity being caused by a decrease in the number and/or speed (energy spectrum shape) of the charge carriers (e.g. Carlson, 1994). The FAC magnitude is also related to the electric field enhancement and hence the flow velocity enhancement. Such a relationship between optical luminosity and flow velocity has previously been observed by Aiko et al. (1993). After $0125 \mathrm{UT}$, when backscatter associated with the sunward flow is no longer observed, the optical arc remains visible until approximately 0230 UT.

In this interpretation, the location of the backscatter observed by the radar is independent of the electrodynamics of the arc system. The mechanism by which irregularities are generated or viewing conditions are satisfied in this region (see Milan et al., 1997) is unknown, but provides a window through which the plasma flow associated with the arc system can be observed.

\subsection{Spatial variation: high latitude or polar arc system}

It was shown in Sect. 3.2 that the region of backscatter observed by the radar remained stationary throughout the period 0036 UT to 0124 UT. This indicates a fairly static flow pattern (though with varying velocities), producing an apparent rapid poleward expansion of backscatter along the MSP meridian after 0104 UT as the MSP location rotates underneath it. If the same interpretation is applied to the optical observations, i.e. that the luminosity features are static and that motion along the MSP meridian is only apparent motion, then the arcs can be projected onto the GMLAT/MLT frame. This is illustrated in Fig. 7, superimposed on the radar backscatter observations from 0112 UT (of Fig. 4c). Figure 7, then, is a projection of temporally varying one-dimensional optical observations into a temporally static two-dimensional, or spatial, feature. This is superimposed on an instantaneous backscatter observation, which is taken to be representative of a temporally static flow pattern, due to its already demonstrated longevity. In this scheme, the most poleward optical arc is coincident with the westernmost edge of the backscatter feature, and continues to higher latitudes, appearing to describe a sun-aligned polar arc (Ismail et al., 1977; Gussenhoven, 1982; Carlson, 1994), a characteristic feature of the polar cap under IMF $B_{\mathrm{z}}>0 \mathrm{nT}$ conditions. The optical arc and the region of sunward plasma flow extend as far anti-sunward as the night side auroral zone, a feature of so-called theta aurora (Frank et al., 1986). The location of the arc in the dawn sector agrees with the expected location of high latitude sun-aligned luminosity features for IMF $B_{\mathrm{y}}<0 \mathrm{nT}$ (Elphinstone et al., 1990).

The location of the arc can be placed in the context of the general dawn-side auroral zone FAC structure of Iijima and Potemra (1976), in which a downward FAC region (region 1) is poleward of an upward $\mathrm{FAC}$ region (region 2). The downward FAC, necessary for the convection reversal between anti-sunward flow in the 


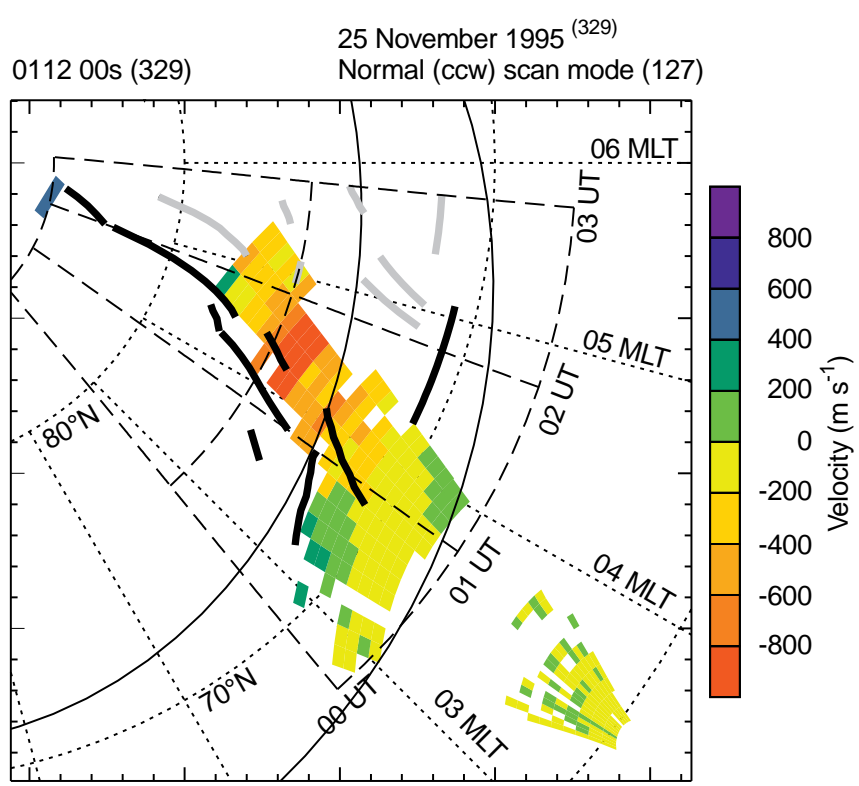

Fig. 7. The locations of optical features presented in FIGURE 3 projected into GMLAT/MLT coordinates for a projection altitude of $250 \mathrm{~km}$, superimposed on a spatial plot of the CUTLASS Finland backscatter velocities measured at 0112 UT. This projection is based on the time-independent hypothesis described in the text. The location of the MSP meridian is indicated for $00 \mathrm{UT}, 01 \mathrm{UT}, 02 \mathrm{UT}$, and 03 $\mathrm{UT}$, as are the projection of zenith angles $0^{\circ}$ and $\pm 80^{\circ}$. The location of the $K_{\mathrm{p}}=1$ auroral oval is also indicated for 0112 UT. Optical arcs indicated in grey are thought to be associated with an auroral activation after $0205 \mathrm{UT}$, and as such time-dependent and not appropriate for this mapping

polar cap and sunward return flow at lower latitudes, is carried by upward-going thermal electrons $(E<100 \mathrm{eV})$ and is associated with the poleward diffuse auroral region (Elphinstone et al., 1993). Embedded within this region is structured electron precipitation $(0.1$ to $1 \mathrm{keV})$ which produces sun-aligned polar arc phenomena (Yamamoto et al., 1993; Elphinstone et al., 1993).
Feldstein et al. (1995) employed Viking and DMSP satellite data to illustrate the case of a theta aurora associated with an overall downward FAC, but within which were embedded small-scale upward FACs of electron precipitation producing fine-structured optical emissions. During IMF $B_{\mathrm{z}}>0 \mathrm{nT}$ conditions the downward FAC region can extend to very high latitudes to form the horse-collar auroral structure of Hones et al., (1989). Indeed, the location and alignment of the observed arc is reminiscent of this horse-collar auroral configuration and a teardrop-shaped polar cap (Murphree et al., 1982; Elphinstone et al., 1993), illustrated in Fig. 8a. Such an auroral configuration is a consequence of low-latitude boundary layer (LLBL) field lines becoming closed during $B_{\mathrm{x}}>0 \mathrm{nT}$ and $B_{\mathrm{y}}, B_{\mathrm{z}} \geq 0 \mathrm{nT}$ conditions (Elphinstone et al., 1990), similar to the prevailing conditions of the present study interval (see Sect. 3). A similar model of the quiet-time polar cap, which is again consistent with the observations, has been discussed by Burch et al. (1992) and Henderson et al. (1996), in which polar arcs and theta aurora mark convection flow reversals between merging and lobe cells (see Fig. 8b), the latter a consequence of high-latitude reconnection of open field lines under $B_{\mathrm{z}}>0 \mathrm{nT}$ conditions. The Henderson et al. (1996) model suggests that the region of backscatter observed by the Finland radar is coincident with a tongue of closed field lines extending across the polar cap, bounded on both sides by open field lines. Both models suggest that polar arcs are associated with flow reversals in the convection flow. This is consistent with the observations as sunward flow is observed to the dawn side of the arc and anti-sunward flow, with line-of-sight velocities of the order of $400 \mathrm{~m} \mathrm{~s}^{-1}$, is observed in the midnight sector polar cap by the Iceland West SuperDARN radar throughout this period.

The flow enhancement observed to progress polewards in the backscatter is now not so directly associated with the electrodynamics of the arc itself, but is a burst in the convection flow. This is perhaps,

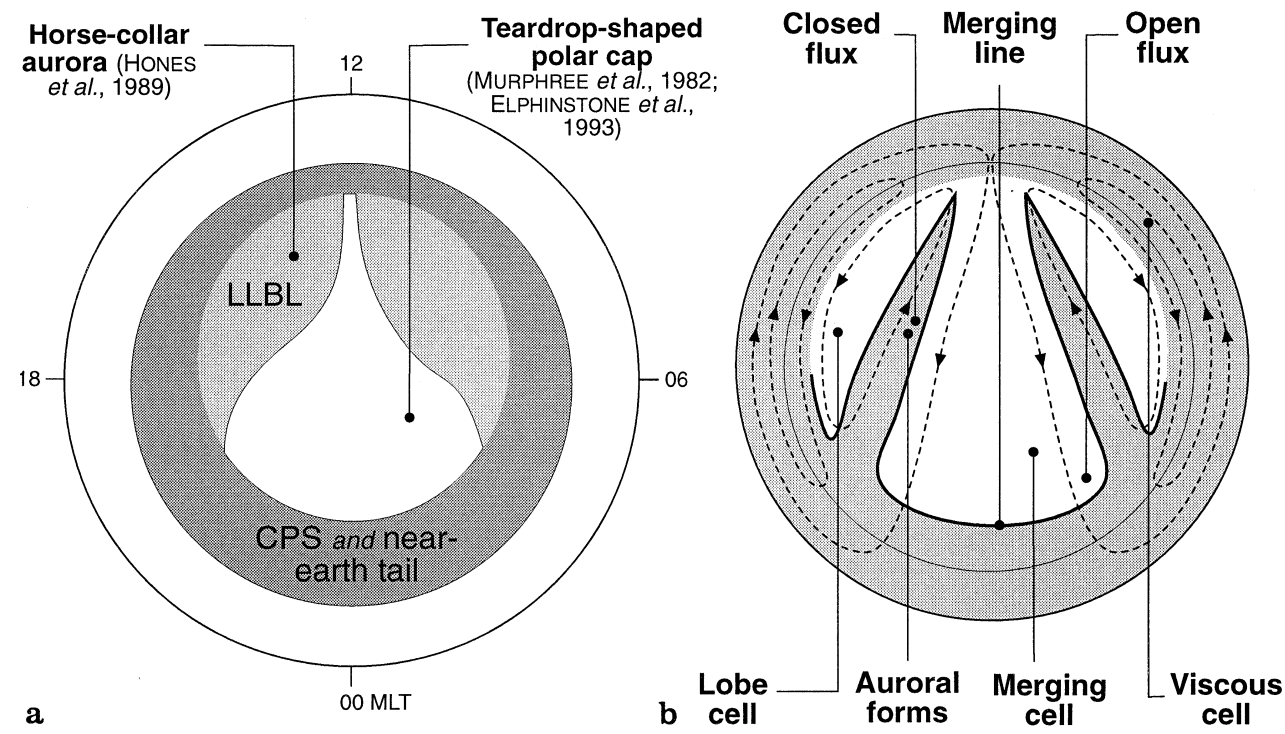

Fig. 8. a The horse-collar auroral configuration (Hones et al., 1989) and teardrop-shaped polar cap (Elphinstone et al., 1993) proposed for northward IMF conditions; b Convection flow (Burch et al., 1992) and open and closed field regions (Henderson et al., 1996) proposed for northward IMF conditions. The tongues of closed flux extending across the "polar cap" are associated with convection reversals and hence polar cap aurora 
then, a manifestation of transient reconnection in the magnetotail and even a bursty bulk flow event (Angelopoulos et al., 1992).

Polar arcs often have a dawn-dusk or dusk-dawn motion, depending on the orientation of IMF $B_{\mathrm{y}}\left(B_{\mathrm{y}}>\right.$ $0 \mathrm{nT}$ or $B_{\mathrm{y}}<0 \mathrm{nT}$ respectively). Too large a drift would invalidate the projection of the arc into the GMLAT/ MLT frame. The stationary nature of the radar backscatter over the $40 \mathrm{~min}$ during which it was observed suggests that in the present case the lateral motion of the arc is negligible. The dusk side edge of the backscatter feature moved less than $1^{\circ}$ in latitude over 40 min (a velocity of less than $50 \mathrm{~m} \mathrm{~s}^{-1}$ ), indicating that the arc itself only moved a maximum of $2^{\circ}$ in latitude, or approximately $200 \mathrm{~km}$ during its 1.5 hour lifetime. The projection of the arc into the GMLAT/MLT frame extends over $10^{\circ}$ in latitude.

In this interpretation, the region of backscatter is more closely related to the location of the arc. It is unclear if the electrodynamics of the arc are associated with irregularity generation (as backscatter is observed to the dawn side of the arc) or suppression (as no backscatter is observed to the dusk side of the arc).

\section{Discussion}

Viewing meridionally scanned optical observations in terms of a temporal variation or a spatial variation leads to two very different interpretations of the data. If only temporal variations are considered then the assumption that auroral arcs are L-shell aligned must be made. It is seen, especially from satellite images, that this is often not the case (e.g. Elphinstone et al., 1990). In this interpretation of the data, the most poleward arc in this MLT sector moves over $5^{\circ}$ of latitude poleward in $45 \mathrm{~min}$. If the motion of this arc is assumed to follow the motion of open-closed field line boundary of the polar cap, then this would presumably be in response to a substorm activation and the closure of open flux. A poleward motion of the open-closed flux boundary from approximately $74^{\circ} \mathrm{N}$ to $79^{\circ} \mathrm{N}$ GMLAT could represent closure of over half of the open flux in the polar cap. No geomagnetic signature of such an event is observed. Alternatively, the polar cap could be displaced towards dusk under the influence of IMF $B_{\mathrm{y}}$, though $B_{\mathrm{y}}$ is small $(-1 \mathrm{nT})$ during this interval. Over the following $45 \mathrm{~min}$, the poleward-most arc progresses to even higher latitudes, indicating the creation of a very small polar cap indeed.

If only spatial variations are considered then the optical features must remain essentially static for up to $1.5 \mathrm{~h}$. It is possible that elements of both interpretations are present in the interval of study. Certainly, not all optical features observed during the three hour period are present at all times: after 0205 UT many bright arcs appear in the optical data, simultaneously with large flow enhancements in the midnight sector being observed by SuperDARN radars to the west of CUTLASS. These arcs are presumed to appear in response to an auroral activation and are not associated with the long-lived poleward-progressing feature; hence they are indicated in grey in the spatial mapping of Fig. 7. The polar cap arc and the boundary of the teardrop-shaped polar cap can be mapped to the flanks of the magnetosphere, the low latitude boundary layer (LLBL), while the lower latitude transient arcs are more probably associated with auroral activity originating in the magnetospheric plasma sheet (Elphinstone et al., 1993).

It would appear that auroral or polar arcs do not present a good target for $\mathrm{HF}$ coherent radars. This indicates that precipitation is not necessarily associated with field-aligned irregularity generation, though this is often cited as an important mechanism (e.g. Tsunoda, 1988). In the first interpretation of the data, no backscatter is produced by the arc, the plasma flow associated with the arc being revealed within a region of pre-existing backscatter. In the second interpretation the auroral arc is associated with the dusk-side edge of an approximately $150 \mathrm{~km}$ wide region of backscatter, though no backscatter is exactly co-located with the arc. Valladares and Carlson (1991) indicate that an approximately $100 \mathrm{~km}$ wide region of enhanced electric field and Joule heating can exist adjacent to a polar arc, a potential region for irregularity generation. However, in the present case the electrodynamics of the arc would suggest that such a region would be located on the dusk side of the optical feature, whereas backscatter is observed to the dawn-side.

\section{Conclusions}

This study presents a comparison of optical observations of a luminosity feature moving polewards along the meridian of a meridian-scanning photometer and measurements of flow velocity within the convection pattern associated with this feature by a coherent HF radar. The results can be interpreted in two ways. The first interpretation is of the rapid poleward motion of an east-west aligned auroral arc. Such events do occur on the nightside when the auroral bulge moves poleward at the end of the substorm expansion phase. No supporting evidence for significant substorm activity can be found, however. The second interpretation is in terms of a longlived (up to $1.5 \mathrm{~h}$ ) sun-aligned polar arc or theta aurora, located between 04 MLT to 05 MLT, a common feature of the high-latitude ionosphere during IMF $B_{\mathrm{z}}>0 \mathrm{nT}$ conditions. The arc is possibly associated with a flowshear in the convection pattern, with sunward flow on the dawn side and anti-sunward flow on the dusk side of the arc. The association with sunward flow is consistent with previous observations of theta aurora (Frank et al., 1986) and conceptual models of the quiet-time polar cap (Burch et al., 1992; Henderson et al., 1996). The spectral width of backscatter associated with the polar arc is high. In both interpretations, the luminosity of the optical feature appears to be related to the plasma flow velocity measured by the radar.

The addition of all-sky camera (ASC) observations to the data set would easily identify which of the two interpretations proposed was correct, though unfortu- 
nately no such observations are available for the period of the present study. The polar arc hypothesis presented in this study emphasises that care must be taken in deducing arc motions from MSP observations or ASC keyograms.

Optical arcs do not appear to have direct analogues in HF radar backscatter. Arcs, however, as the visual manifestation of boundaries between different magnetospheric regions, can indicate the interface between different convection flow regimes, which can be identified in HF radar velocity maps. No backscatter (which is not pre-existing) is observed co-located with the arc, indicating that in this instance no significant fieldaligned irregularity generation is associated with the particle precipitation producing the luminosity. That precipitation does not necessarily give rise to irregularities is further supported as little or no radar backscatter is observed associated with the intense auroral arcs observed after 0205 UT. Optical and HF radar observations are complementary techniques, and each provides insight into the interpretation of the other. On the one hand, the optical observations help delineate the boundaries between different flow regimes within the polar cap, and ultimately between different regions within the magnetosphere. On the other hand, the HF radar observations allow the differentiation between spatial and temporal variations within the optical data and provide information concerning plasma flow associated with the electrodynamics of the ionospheremagnetosphere system.

Acknowledgements. CUTLASS is supported by the Particle Physics and Astronomy Research Council (PPARC), UK, the Swedish Institute for Space Physics, Uppsala, and the Finnish Meteorological Institute, Helsinki. The IMAGE magnetometer data employed in this study were collected as a German-FinnishNorwegian-Polish project conducted by the Geophysical Research Division of the Finnish Meteorological Institute (FMI/GEO). The WIND MFI observations were provided by R. P. Lepping of the Laboratory for Extraterrestrial Physics, NASA/Goddard Space Flight Centre, MD, USA.

Topical Editor: D. Alcaydé thanks G. Marklund and H. U. Frey for their help in evaluating this work.

\section{References}

Aikio A. T., H. J. Opgenoorth, M. A. I. Persson, and K. U. Kaila, Ground-based measurements of an arc-associated electric field, J. Atmos. Terr. Phys., 55, 797-808, 1993.

Angelopoulos V., W. Baumjohann, C. F. Kennel, F. V. Coroniti, M. G. Kivelson, R. Pellat, R. J. Walker, H. Lühr, and G. Paschmann, Bursty bulk flows in the inner central plasma sheet, J. Geophys. Res., 97, 4027-4039, 1992.

Baker K. B., and S. Wing, A new magnetic coordinate system for conjugate studies at high latitudes, J. Geophys. Res., 94, 91399143, 1989.

Beaujardiere O. De La, R. Vondrak, and M. Baron, Radar observations of electric fields and current associated with auroral arcs. J. Geophys. Res., 82, 5051-5062, 1977.

Buneman O, Excitation of field aligned sound waves by electron streams, Phys. Rev. Lett., 10, 285-287, 1963.

Burch J. L., S. A. Fields, and R. A. Heelis, Polar cap electron acceleration regions, J. Geophys. Res., 84, 5863-5874, 1979.
Burch J. L., N. A. Saflekos, D. A. Gurnett, J. D. Craven, and L. A. Frank, The quiet time polar cap: DE 1 observations and conceptual model, J. Geophys. Res., 97, 19403-19412, 1992.

Burke W. J., M. S. Gussenhoven, M. C. Kelley, D. A. Hardy, and F. J. Rich, Electric and magnetic field characteristics of discrete arcs in the polar cap, J. Geophys. Res., 87, 2431-2443, 1982

Carlson H. C., The dark polar ionosphere: progress and future challenges, Radio Sci., 29, 157-165, 1994.

Carlson H. C., R. A. Heelis, E. J. Weber, and J. R. Sharber, Coherent mesoscale convection patterns during northward interplanetary magnetic field, J. Geophys. Res., 93, 1450114514, 1988.

Elphinstone R. D., K. Jankowska, J. S. Murphree, and L. L. Cogger, The configuration of the auroral distribution for interplanetary magnetic field $B_{\mathrm{z}}$ northward 1. IMF $\mathrm{B}_{\mathrm{x}}$ and $\mathrm{B}_{\mathrm{y}}$ dependencies as observed by the Viking satellite, J. Geophys. Res., 95, 57915804, 1990.

Elphinstone R. D., J. S. Murphree, D. J. Hearn, W. Heikkila, M. G. Henderson, L.L. Cogger, and I. Sandahl, The auroral distribution and its mapping according to substorm phase, J. Atmos. Terr. Phys., 55, 1741-1762, 1993.

Farley D. T., A plasma instability resulting in field-aligned irregularities in the ionosphere, J. Geophys. Res., 63, 60836097, 1963.

Feldstein Y. I., P. T. Newell, I. Sandahl, J. Woch, S. V. Leontjev, and V. G. Vorobjev, Structure of auroral precipitation during a theta aurora from multisatellite observations, J. Geophys. Res., 100, 17429-17442, 1995.

Feldstein Y. I., and G. V. Starkov, Dynamics of auroral belt and polar geomagnetic disturbances, Planet. Space Sci., 15, 209230, 1967.

Frank L. A., J. D. Craven, D. A. Gurnett, S. D. Shawhan, D. R. Weimer, J. L. Burch, J. D. Winningham, C. R. Chappel, J. H. Waite, R. A. Heellis, N. C. Maynard, M. Sigiura, W. K. Peterson, and E. G. Shelley, The theta aurora, J. Geophys. Res., 92, 3177-3224, 1986.

Frey H. U., G. Haerendel, D. Knudsen, S. Buchert, and O. H. Bauer, Optical and radar observations of the motion of auroral arcs, $J$. Atmos. Terr. Phys., 58, 57-69, 1996.

Gazey N. G. J., M. Lockwood, P. N. Smith, S. Coles, R. J. Bunting, M. Lester, A. D. Aylward, T. K. Yeoman, and H. Lühr, Development of substorm cross-tail current disruption as seen from the ground, J. Geophys. Res., 100, 9633-9648, 1995.

Greenwald R. A., K. B. Baker, J. R. Dudeney, M. Pinnock, T. B. Jones, E. C. Thomas, J.-P. Villain, J.-C. Cerisier, C. Senior, C. Hanuise, R. D. Hunsucker, G. Sofko, J. Koehler, E. Nielsen, R. Pellinen, A. D. M. Walker, N. Sato, and H. Yamagishi, DARN/ SuperDARN: a global view of the dynamics of high-latitude convection, Space Sci. Rev., 71, 761-796, 1995.

Gussenhoven M.S., Extremely high latitude auroras, J. Geophys. Res., 87, 2401-2412, 1982.

Hanuise C., J. P. Villain, D. Gresillon, B. Cabrit, R. A. Greenwald, and K. B. Baker, Interpretation of HF radar ionospheric Doppler spectra by collective wave scattering theory, Ann. Geophysicae, 11, 29-39, 1993.

Henderson M. G., J. S. Murphree, and J. M. Weygand, Observations of auroral substorms occurring together with preexisting "quiet time" auroral patterns, J. Geophys. Res., 101, 2462124640, 1996.

Holzworth R. H., and C. -I. Meng, Mathematical representation of the auroral oval, Geophys. Res. Lett., 2, 377-380, 1975.

Hones E. W., J. D. Craven, L. A. Frank, D. S. Evans, and P. T. Newell, The horse-collar aurora - a frequent pattern of the aurora in quiet times, Geophys. Res. Lett., 16, 37-40, 1989.

Iijima T., and T. A. Potemra, The amplitude distribution of fieldaligned currents at northern high latitudes observed by TRIAD, J. Geophys. Res., 81, 2165-2174, 1976.

Ismail S., D. D. Wallis, and L. L. Cogger, Characteristics of polar cap Sun-aligned arcs, J. Geophys. Res., 82, 4741-4749, 1977. 
Marklund G., Auroral arc classification scheme based on the observed arc-associated electric filed pattern, Planet. Space Sci., 32, 193-211, 1984.

Milan S. E., T. K. Yeoman, M. Lester, E. C. Thomas, and T. B. Jones, Initial backscatter occurrence statistics from the CUTLASS HF radars, Ann. Geophysicae, 15, 703-718, 1997.

Murphree J. S., C. D. Anger, and L. L. Cogger, The instantaneous relationship between polar cap and oval auroras at times of northward interplanetary magnetic field, Can. J. Phys., 60, 349 356, 1982.

Opgenoorth H. J., I. Häggström, P. J. S. Williams, and G. O. L. Jones, Regions of strongly enhanced perpendicular electric fields adjacent to auroral arcs, J. Atmos. Terr. Phys., 52, 449458, 1990.

Ossakow S. L., and P. K. Chaturvedi, Current convective instability in the diffuse aurora, Geophys. Res. Lett., 6, 323, 334, 1979.

Ruohoniemi J. M., R. A. Greenwald, K. B. Baker, J. P. Villain, and M.A. McCready, Drift motions of small-scale irregularities in the high-latitude F region: an experimental comparison with plasma drift motions, J. Geophys. Res., 92, 4553-4564, 1987.

Tsunoda R. T., High latitude F region irregularities: a review and synthesis, Rev. Geophys., 26, 719-760, 1988.

Valladares C. E., and H. C. Carlson, The electrodynamic, thermal, and energetic character of intense sun-aligned arcs in the polar cap, J. Geophys. Res., 96, 1379-1400, 1991.

Villain J. P., G. Caudal, and C. Hanuise, A SAFARI-EISCAT comparison between the velocity of $\mathrm{F}$ region small-scale irregularities and the ion drift, J. Geophys. Res., 90, 8433$8443,1985$.

Yamamoto T., E. Kaneda, H. Hayakawa, T. Mukai, A. Matsouka, S. Machinda, H. Fukunisha, N. Kaya, K. Tsuruda, and A. Nishida, Meridional structures of electric potentials relevant to premidnight discrete auroras: a case study from Akebono measurements, J. Geophys. Res., 98, 11135-11151, 1993. 